\title{
Mortality trends in chronic liver disease and cirrhosis from 1981 to 2015 in Taiwan
}

\author{
Shih-Yung Su ${ }^{1,2 \dagger}$, Long-Teng Lee ${ }^{3,4 \dagger}$ and Wen-Chung Lee ${ }^{1,2^{*}}$ (D)
}

\begin{abstract}
Background: Globally, the morbidity and mortality rates for chronic liver disease and cirrhosis are increasing. The National Viral Hepatitis Therapy Program in Taiwan was implemented in 2003, but evidence regarding the program's effect on the trends of mortality for chronic liver disease and cirrhosis is limited.

Methods: We analyzed mortality rates for chronic liver disease and cirrhosis in Taiwan for the period from 1981 to 2015. An autoregressive age-period-cohort model was used to estimate age, period, and cohort effects.

Results: Age-adjusted mortality rates for chronic liver disease and cirrhosis all displayed a flat but variable trend from 1981 to 2004 and a decreasing trend thereafter for both sexes. The age-period-cohort model revealed differential age gradients between the two sexes; mortality rates in the oldest age group (90-94 years) were 12 and 66 times higher than those in the youngest age group (30-34 years) for men and women, respectively. The period effects indicated that mortality rates declined after 2004 in both sexes. Mortality rates decreased in men but increased in women in the 1891-1940 birth cohorts and increased in both sexes in the birth cohorts from 1950 onward.
\end{abstract}

Conclusions: The National Viral Hepatitis Therapy Program in Taiwan may have contributed to the decrease in mortality rates for chronic liver disease and cirrhosis in adulthood.

Keywords: Mortality, Chronic liver disease, Liver cirrhosis, Age-period-cohort model

\section{Background}

Chronic liver disease and cirrhosis can progress to hepatocellular carcinoma. Global estimates indicate that chronic liver disease and liver cirrhosis account for more than 2 and 1 million deaths annually, respectively [1]. Furthermore, the morbidity and mortality rates for chronic liver disease and cirrhosis are increasing, despite most cases being preventable [2,3]. Together, chronic liver disease and cirrhosis were the 12th leading cause of death in the United States in 2015, accounting for 12.5 deaths per 100,000 people [4]. In Taiwan, chronic liver

\footnotetext{
*Correspondence: wenchung@ntu.edu.tw

${ }^{\dagger}$ Shih-Yung Su and Long-Teng Lee equally contributed to this work ${ }^{1}$ Institute of Epidemiology and Preventive Medicine, College of Public Health, National Taiwan University, Xuzhou Rd., Rm. 536, No. 17, Taipei 100, Taiwan

Full list of author information is available at the end of the article
}

disease and cirrhosis constituted the tenth leading cause of death in both the sexes in 2015 (20 deaths per 100,000 people) [5].

Risk factors for chronic liver disease, cirrhosis, and liver cancer include hepatitis B virus (HBV) infection, hepatitis $\mathrm{C}$ virus (HCV) infection, excessive alcohol drinking, cigarette smoking, and obesity [6,7]. In Taiwan, more than $90 \%$ of cases of end-stage liver diseases were related to $\mathrm{HBV}$ and $\mathrm{HCV}$ infection [8]. To address the growing burden of liver disease, the National HBV Vaccination Program for all infants in Taiwan was implemented in 1984 [9]. Several studies have demonstrated that the National HBV Vaccination Program has significantly reduced the incidence of and mortality from endstage liver disease in children and adolescents born after 1984 [10-13]. Another nationwide program, namely the National Viral Hepatitis Therapy Program, was implemented in Taiwan in 2003 [9]. A study demonstrated that original author(s) and the source, provide a link to the Creative Commons licence, and indicate if changes were made. The images or other third party material in this article are included in the article's Creative Commons licence, unless indicated otherwise in a credit line to the material. If material is not included in the article's Creative Commons licence and your intended use is not permitted by statutory regulation or exceeds the permitted use, you will need to obtain permission directly from the copyright holder. To view a copy of this licence, visit http://creativecommons.org/licenses/by/4.0/. The Creative Commons Public Domain Dedication waiver (http://creativeco mmons.org/publicdomain/zero/1.0/) applies to the data made available in this article, unless otherwise stated in a credit line to the data. 
since its implementation, this program has reduced mortality rates for chronic liver disease, cirrhosis, and liver cancer [14]. However, the study did not consider birth cohort effects.

In the present study, we used an autoregressive ageperiod-cohort model to analyze mortality trends for chronic liver disease and cirrhosis in Taiwan from 1981 to 2015. Age-period-cohort analysis can help demonstrate the influence of health policy, medical technology, public hazard events, and large-scale environmental events on disease incidence and mortality rates. Accordingly, the effects of three temporal factors, namely age, period, and cohort, on mortality rates for chronic liver disease and cirrhosis as well as the effects of the National HBV Vaccination Program and Viral Hepatitis Therapy Program were discussed.

\section{Methods}

\section{Data sources}

All causes of death in Taiwan for the period from 1981 to 2015 were extracted from an online database provided by the Ministry of Health and Welfare. In this study, cases of mortality for chronic liver disease and cirrhosis were selected using International Classification of Diseases, Ninth Revision (ICD-9) code 571 (for the period 1981-2007), and ICD-10 codes K70, K73, and K74 (for the period after 2008). Chronic liver disease and cirrhosis were aggregated in this study because these two causes of death share the same ICD-9 code. The use of the two coding systems resulted in an estimated difference of $<3 \%$ in the numbers of cases of chronic liver disease and cirrhosis [15]. Data for 146,881 cases of mortality for chronic liver disease and cirrhosis $(107,616$ in men and 39,265 in women aged 30-94 years) for the period from 1981 to 2015 were collected. Patients aged younger than 30 years were not included because of the paucity of mortality cases for this age group. The data were categorized into 13 age groups (from 30-34 to 90-94 years) and 7 period groups (from 1981-1985 to 2011-2015). Midyear population data in Taiwan from 1981 to 2015 were extracted from the online database provided by the Department of Statistics of the Ministry of the Interior, in which data were similarly categorized into 13 age and 7 period groups.

\section{Statistical analysis}

Age-specific mortality rates according to age, period, and cohort were calculated for both sexes and plotted on a $\log$ scale. Age-adjusted mortality rates for chronic liver disease and cirrhosis were calculated using the World Health Organization 2000 World Standard Population for both sexes. The average annual percentage change in mortality for chronic liver disease and cirrhosis between 1981 and 2003 (before the implementation of the National Viral Hepatitis Therapy Program) and that between 2004 and 2015 (after program implementation) were calculated. The hierarchy of age-period-cohort modeling strategy proposed by Clayton and Schifflers $[16,17]$ was used to evaluate the effects of age, period, and cohort through a log-linear Poisson model. All three temporal factors were included in the model. In addition, three two-factor models (namely age and period, age and cohort, and period and cohort) were considered. A likelihood ratio test was performed between the age-period-cohort model and the two-factor models to determine an appropriate model to fit the mortality data of chronic liver disease and cirrhosis. However, the age-period-cohort model exhibited nonidentifiability problem owing to the exact linear relation of the three temporal variables $($ cohort + age $=$ period). A nonidentifiable age-period-cohort model typically produces an infinite set of parameter estimates with equal goodnessof-fit indices. To avoid this problem, an autoregressive age-period-cohort model was used in this study to estimate the age, period, and cohort effects [18]. Autoregressive age-period-cohort models assume a first-order autoregressive process for the cohort effects; hence, they do not have nonidentifiability problem. Autoregressive age-period-cohort models have been demonstrated to be effective in estimating disease incidence and mortality [19].

All statistical analyses were performed using SAS statistical software version 9.4 (SAS ${ }^{\circledR}$ Institute Inc, Cary, NC, USA).

\section{Results}

Figure 1 illustrates the secular trends in the annual ageadjusted mortality rates for chronic liver disease and cirrhosis in men and women in Taiwan from 1981 to 2015. The trends observed for both sexes were similar, but the age-adjusted mortality rate in men was considerably higher than that in women (approximately threefold). For the two sexes, we observed a flat but fluctuating trend from 1981 to 2004 and a decreasing trend thereafter; the decreasing trend was particularly pronounced in women.

Table 1 presents the average annual percentage change in mortality for chronic liver disease and cirrhosis between 1981 and 2003 and that between 2004 and 2015 in Taiwan. For men, a slight yearly decrease in age-adjusted mortality was observed from 1981 to 2003 ( $-0.56 \%$ per annum), and a more pronounced decrease was recorded from 1981 to $2003(-2.28 \%$ per annum). For women, a slight increase in age-adjusted mortality was observed between 1981 and 2003 (0.12\% per annum), followed by a decrease from 2004 to 2015 $(-4.82 \%$ per annum). The trends in mortality rates 


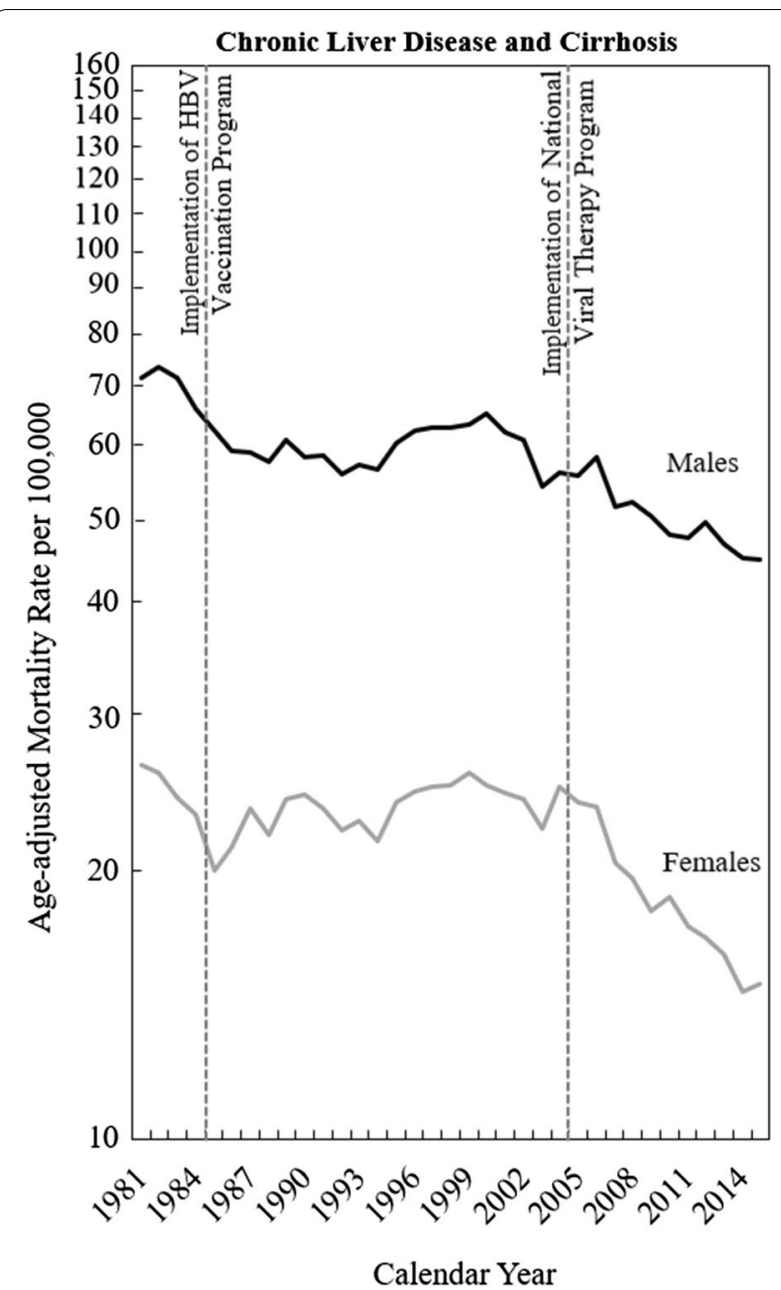

Fig. 1 Age-adjusted mortality rates from chronic liver disease and liver cirrhosis in Taiwan

were consistent across all age groups for men (except for the 75-89-year age groups) and women (except for the 45-49-year age group).

Figure 2 presents a simple graphical depiction of chronic liver disease and cirrhosis data for men (upper panels) and women (lower panels). The data for men indicated that mortality rates for chronic liver disease and cirrhosis in the oldest age group (90-94 years) were approximately 20 times higher than those in the youngest age group (30-34 years) (Fig. 2A). The period trend for men (Fig. 2B) revealed that mortality rates increased from 1981 to 2000 and decreased after 2000 in the younger age groups (30-59 years). In the older age groups (60-94 years), mortality rates exhibited a long-term decreasing trend from 1981 to 2015. The birth cohort data for men (Fig. 2C) showed that mortality trends decreased slowly from 1891 to 1946, increased drastically from 1946 to 1966, and decreased thereafter. The data for women indicated that mortality rates for chronic liver disease and cirrhosis in the oldest age group (90-94 years) were approximately 80 times higher than those in the youngest age group (30-34 years) (Fig. 2D). The period trend for women (Fig. 2E) revealed that mortality rates were flat but fluctuating in the younger age groups (30-49 years). In the older age groups (50-94 years), mortality rates exhibited a slightly increasing trend initially, followed by a decreasing trend. The birth-cohort trends for women (Fig. 2F) demonstrated that mortality rates increased slowly from 1891 to 1941, decreased drastically from 1941 to 1951, and leveled off after 1951.

Table 2 presents the likelihood ratio test results for the model hierarchy. For men, the age-period-cohort model exhibited the lowest deviance (436.05). The likelihood ratio test results for the one-factor models and twofactor models all exhibited significantly higher deviance than did the results for the age-period-cohort model. For women, the age-period-cohort model exhibited the lowest deviance (129.29), and all other models exhibited significantly higher deviance. The likelihood ratio test results indicate that all three temporal variables should be considered for both sexes when modeling mortality rates for chronic liver disease and cirrhosis.

Figure 3 displays the results of age-period-cohort modeling for men (upper panels) and women (lower panels). For men, mortality rates were 12 times higher in the oldest age group (90-94 years) than in the youngest age group (30-34 years). The period effect exhibited a flat but slightly variable trend from 1981 to 2000 and a decreasing trend thereafter. Moreover, the relative risk of mortality for chronic liver disease and cirrhosis from 2011 to 2015 was $37 \%$ lower than that from 1996 to 2000 . The cohort effect decreased slightly from 1891 to 1946, increased from 1946 to 1971, and leveled off in the recent birth cohorts. For women, mortality rates were 66 times higher in the oldest age group (90-94 years) than in the youngest age group (30-34 years). The period effect exhibited a slightly increasing trend from 1981 to 2000 , followed by a decreasing trend. Furthermore, the relative risk of mortality for chronic liver disease and cirrhosis from 2011 to 2015 was $30 \%$ lower than that from 1996 to 2000 . The cohort effect exhibited an increasing trend from 1891 to 1941, a suddenly decreasing trend from 1941 to 1951, and an increasing trend after 1951.

\section{Discussion}

This study revealed that mortality rates for chronic liver disease and cirrhosis in the oldest age group (9094 years) were 12 and 66 times higher than those in the 
Table 1 The average annual percentage change of age-adjusted rates and age-specific rates of chronic liver disease and cirrhosis between 1981 and 2003, and between 2004 and 2015 for men and women in Taiwan

\begin{tabular}{|c|c|c|c|c|c|c|}
\hline & \multicolumn{3}{|l|}{ Men } & \multicolumn{3}{|l|}{ Women } \\
\hline & $\begin{array}{l}\text { Between } 1981 \text { and } \\
2003(\%)\end{array}$ & $\begin{array}{l}\text { Between } 2004 \text { and } \\
2015(\%)\end{array}$ & Change* $(\%)$ & $\begin{array}{l}\text { Between } 1981 \text { and } \\
2003(\%)\end{array}$ & $\begin{array}{l}\text { Between } 2004 \text { and } \\
2015 \text { (\%) }\end{array}$ & Change* $(\%)$ \\
\hline Age-adjusted rates & -0.56 & -2.28 & -1.73 & 0.12 & -4.82 & -4.94 \\
\hline \multicolumn{7}{|l|}{ Age-specific rates } \\
\hline $30-34$ & 2.30 & -4.39 & -6.69 & 1.60 & -4.15 & -5.75 \\
\hline $35-39$ & 2.20 & -2.62 & -4.83 & 0.04 & -1.35 & -1.39 \\
\hline $40-44$ & 1.07 & -1.57 & -2.63 & -0.92 & -4.55 & -3.64 \\
\hline $45-49$ & 0.35 & -0.50 & -0.85 & -0.91 & -0.25 & 0.66 \\
\hline $50-54$ & 0.20 & -0.97 & -1.17 & -1.42 & -3.99 & -2.57 \\
\hline $55-59$ & 0.10 & -1.35 & -1.45 & 0.21 & -5.38 & -5.59 \\
\hline $60-64$ & -0.26 & -6.09 & -5.83 & -0.53 & -9.43 & -8.91 \\
\hline $65-69$ & -1.90 & -4.70 & -2.79 & 0.12 & -6.64 & -6.76 \\
\hline $70-74$ & -2.37 & -3.98 & -1.61 & 0.72 & -4.55 & -5.28 \\
\hline $75-79$ & -3.18 & -2.81 & 0.37 & 1.23 & -4.28 & -5.50 \\
\hline $80-84$ & -3.56 & -2.23 & 1.32 & 1.31 & -2.67 & -3.98 \\
\hline $85-89$ & -3.10 & -2.64 & 0.46 & 1.91 & -3.22 & -5.13 \\
\hline $90-94$ & -3.23 & -5.67 & -2.45 & 1.94 & -3.29 & -5.23 \\
\hline
\end{tabular}

${ }^{*}$ Change $=$ (average annual percentage change between 2004 and 2015) - (average annual percentage change between 1981 and 2003 )

youngest age group (30-34 years) for men and women, respectively. In a study on mortality rates for hepatocellular carcinoma in Taiwan, similar differential age gradients were observed in men and women [19]. Chronic liver disease and cirrhosis can progress to hepatocellular carcinoma, with a 5-year progression risk of approximately 22-28\% [20]. Furthermore, common risk factors for chronic liver disease, cirrhosis, and hepatocellular carcinoma include hepatitis virus infection, alcohol consumption, and metabolic conditions. These common risk factors may partially explain the similarity in mortality rate age gradients for chronic liver disease, cirrhosis, and hepatocellular carcinoma. However, for both sexes, the age gradients in chronic liver disease and cirrhosis mortality rates in Taiwan are lower than the age gradients in Canada and Europe [21, 22]; this warrants further investigation.

When estimating the birth cohort effect, we noted that mortality rates for chronic liver disease and cirrhosis decreased in men but increased in women in the 18911940 birth cohorts. The rates increased in both sexes in the birth cohorts from 1950 onward. Men and women in the 1891-1940 birth cohorts experienced the era of Japanese occupation (1895-1945) and the early postwar period (1945-1949) during their childhood. Living in a changing society may have caused multiple adverse health outcomes. Men and women in the birth cohorts after 1950 experienced industrialization, westernization, urbanization, globalization, and economic growth during their childhood. Previous studies have demonstrated that rapid economic growth and income growth are associated with obesity and high alcohol consumption [23-26]. This may explain in part the increase in male and female mortality rates in these birth cohorts.

This study showed that mortality rates for chronic liver disease and cirrhosis declined after 2004 in both sexes (see Fig. 1, Table 1, and the period effects in Fig. 3). The decrease may have stemmed from the National Viral Hepatitis Therapy Program in Taiwan. This program was launched in 2003 by the National Health Insurance Administration, which provides nearly $100 \%$ health coverage for the Taiwanese population, to reach all patients infected with HBV and HCV [9]. This program reimburses treatments, including lamivudine, interferon $\alpha$, pegylated interferon $\alpha$, entecavir, telbivudine, tenofovir, adefovir, and direct-acting antiviral agents, for patients with viral hepatitis infections. In the early 1980 s, approximately $15 \%$ to $20 \%$ of Taiwanese adults tested positive for HBV surface antigen $[27,28]$, but only approximately $1 \%$ to $2.5 \%$ exhibited HCV infection [29-31]. However, antiviral therapy for $\mathrm{HBV}$ infection was reported to be less effective than that for HCV infection [32]. The effect of antiviral therapy in eliminating $\mathrm{HBV}$ has been reported to be limited [33, 34]. Another study indicated that the antiviral therapy program was ineffective in reducing mortality for acute and chronic viral hepatitis in Taiwan [35]. Although the role of antiviral therapy in eliminating HBV was unclear, several studies have demonstrated 


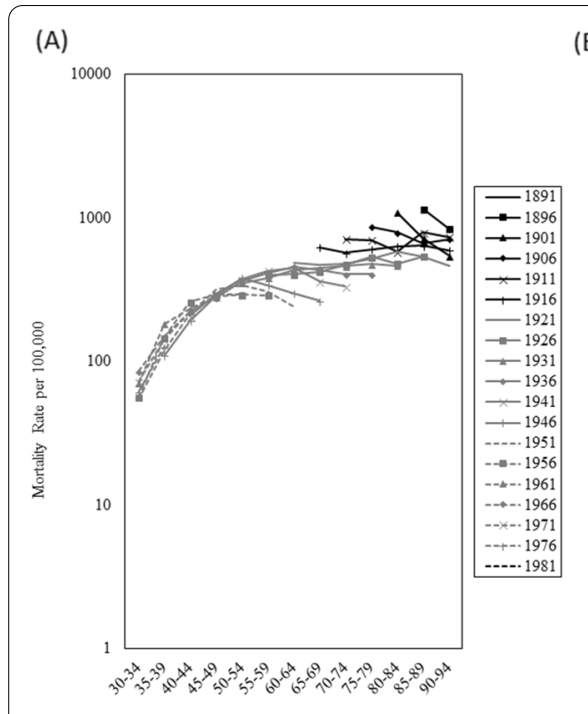

(B)

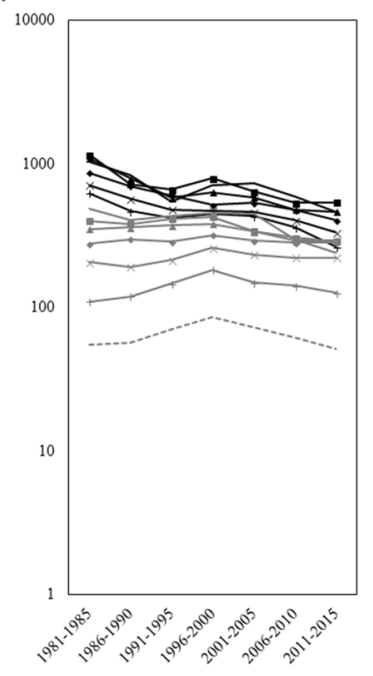

(D)

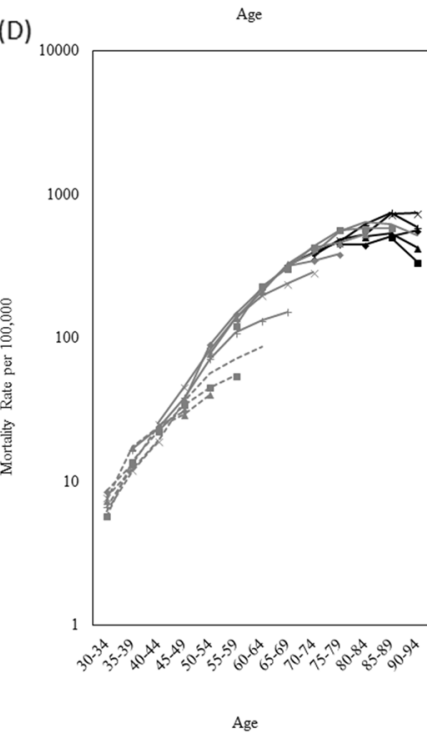

(E)

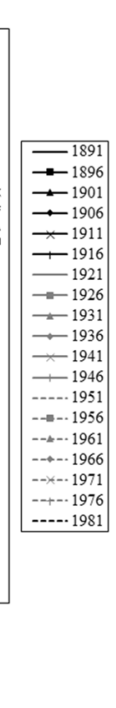

(E)

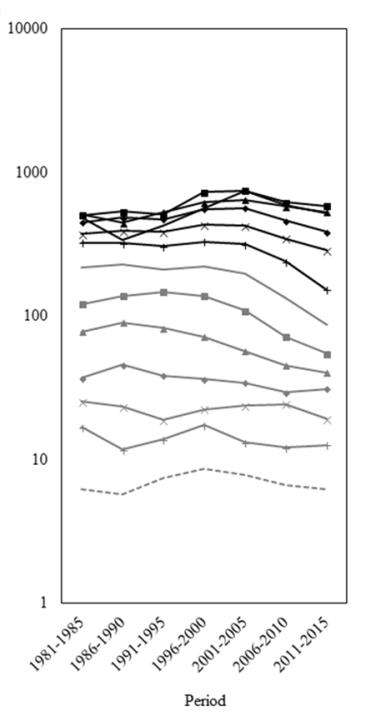

(C)

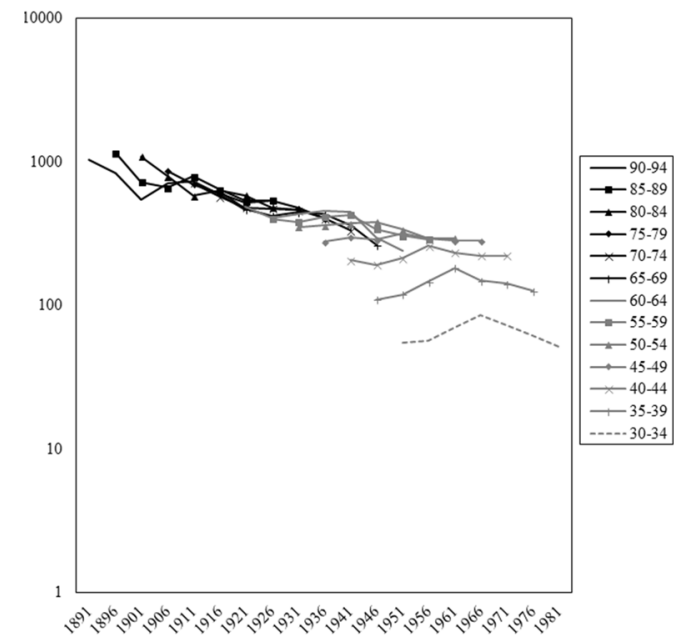

(F) ${ }_{10000}$
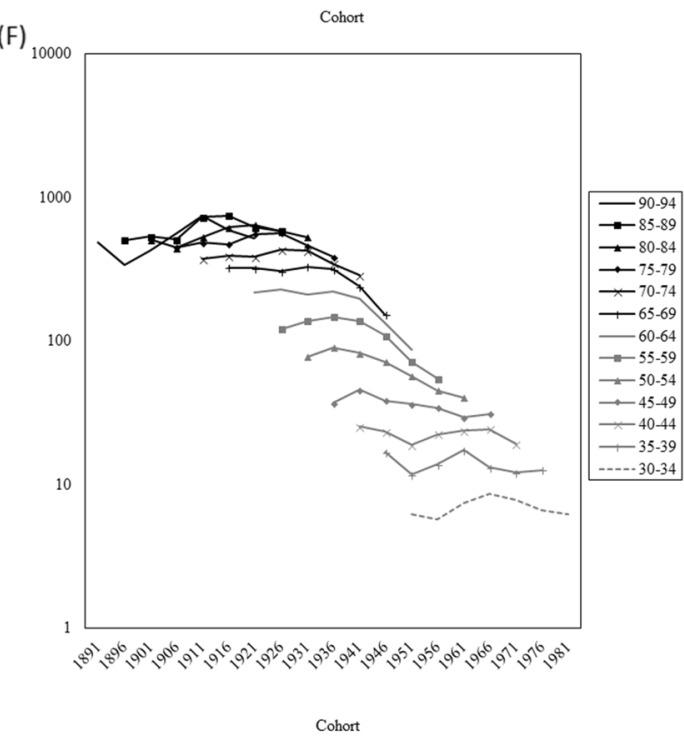

Fig. 2 Age-specific mortality rates from chronic liver disease and liver cirrhosis in Taiwan. Upper panels (A-C) for men and lower panels (D-F) for women

that the antiviral therapies lamivudine, entecavir, and telbivudine could substantially reduce inflammation and fibrosis in the liver, prevent liver failure for patients with liver cirrhosis, and significantly reduce mortality for liver cirrhosis and liver cancer [34, 36-38]. Our study results are consistent with those of a previous study in which an age-period model indicated that the program may have reduced mortality rates for chronic liver disease and cirrhosis in Taiwan [14].

The possibility of chronic liver disease and cirrhosis progressing to hepatocellular carcinoma is high. A previous study using the same autoregressive age-periodcohort model as the present study reported an increasing trend for hepatocellular carcinoma mortality from 1976 to 2005 [19]. However, the data collection period ended in 2005, and conclusions could not be drawn on whether the trend would continue to increase or start declining after 2005. We performed additional analyses to examine the effect of the National Viral Hepatitis Therapy Program on liver cancer mortality. The age-adjusted liver cancer mortality rates (30 to 94 years old) displayed increasing trends from 1981 to 2003 and decreasing trends from 2004 to 2015 for both sexes (Additional file 1: Figure S1). Similar findings were also noted in agespecific mortality rates for both sexes (Additional file 1: Table S1). These findings are also consistent with those of a previous study [14]. We also performed additional analyses to examine the effect of the National Viral Hepatitis 


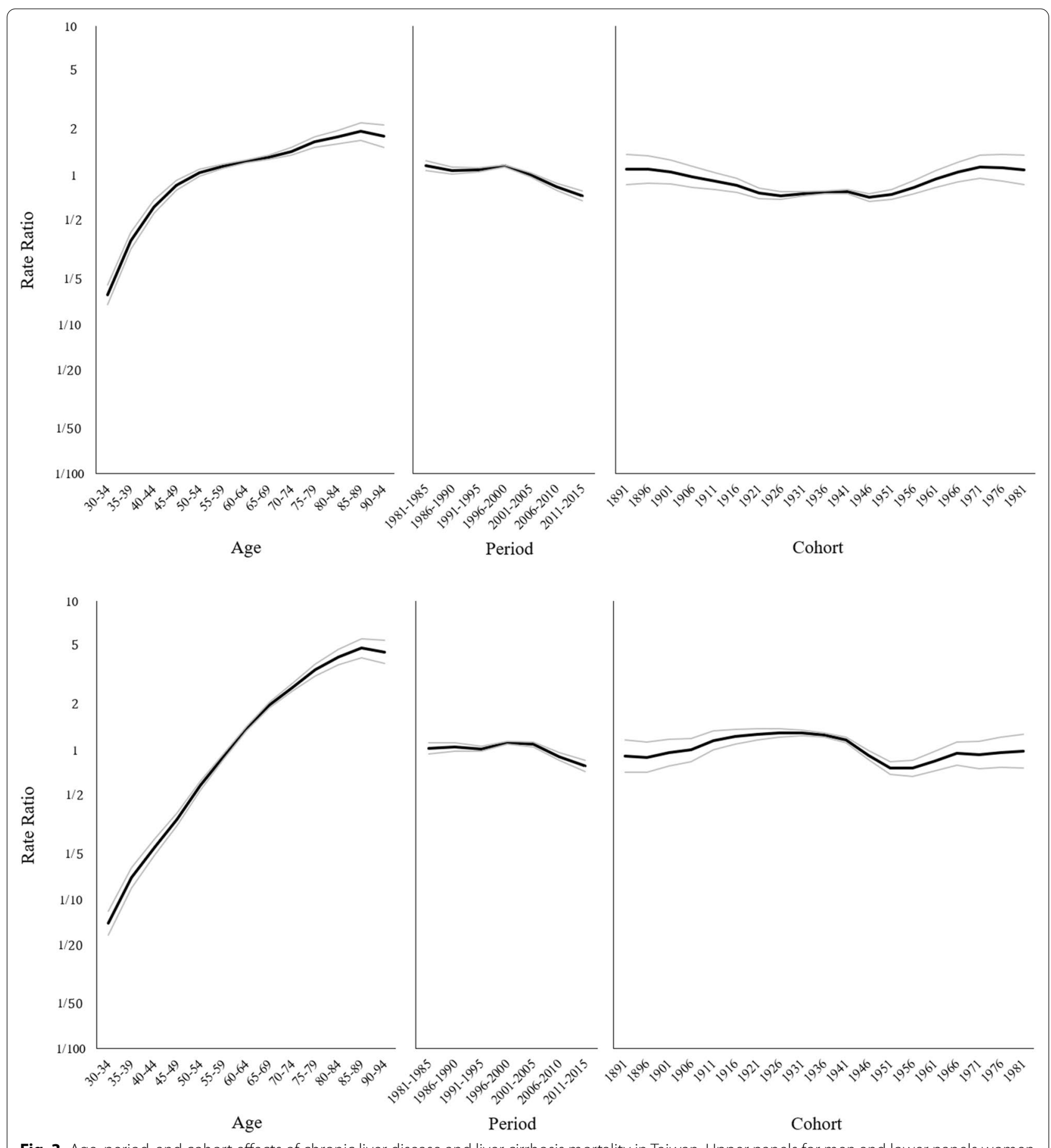

Fig. 3 Age, period, and cohort effects of chronic liver disease and liver cirrhosis mortality in Taiwan. Upper panels for men and lower panels women

Therapy Program on the age distribution of chronic liver disease and cirrhosis mortality. The same autoregressive age-period-cohort model was used to analyze the data before and after the implementation of the nationwide program. The results indicated that for both sexes, the age effects before program implementation were similar to those after program implementation (Additional file 1: Figure S2).

Taiwan was previously a hyperendemic region for HBV infection [39, 40]. The National HBV Vaccination 
Table 2 Age-period-cohort model for chronic liver disease and liver cirrhosis mortality rates in Taiwan

\begin{tabular}{lrrll}
\hline Models & df & Deviance & $\begin{array}{l}\text { Likelihood ratio } \\
\text { statistic (df) }\end{array}$ & P value \\
\hline Males & & & & \\
Age & 78 & 3013.15 & $2577.10(23)$ & $<0.0001$ \\
Period & 84 & $33,327.97$ & $32,891.92(29)$ & $<0.0001$ \\
Cohort & 72 & $11,177.27$ & $10,741.22(17)$ & $<0.0001$ \\
AP & 72 & 1470.36 & $1034.31(17)$ & $<0.0001$ \\
AC & 60 & 1155.41 & $719.36(5)$ & $<0.0001$ \\
PC & 66 & 6502.79 & $6066.74(11)$ & $<0.0001$ \\
APC & 55 & 436.05 & Reference & Reference \\
Females & & & & $<0.0001$ \\
Age & 78 & 2045.93 & $1916.64(23)$ & $<0.0001$ \\
Period & 84 & $60,272.85$ & $60,143.56(29)$ & $<0.0001$ \\
Cohort & 72 & $11,457.84$ & $11,328.55(17)$ & $<0.0001$ \\
AP & 72 & 812.07 & $682.78(17)$ & $<0.0001$ \\
AC & 60 & 450.82 & $321.53(5)$ & $<0.0001$ \\
PC & 66 & 1265.24 & $1135.95(11)$ & Reference \\
APC & 55 & 129.29 & Reference &
\end{tabular}

df: degree of freedom; Likelihood ratio statistic: increase in deviance from the APC model; df*: increase in df from the APC model; APC: full age-period-cohort model; AC: age-cohort model; AP: age-period model; PC: period-cohort model

Program for all infants born after 1984 has converted Taiwan into a low-endemic region [41]. The reduction of mortality rates for chronic liver disease and cirrhosis observed in our study was not attributable to the National HBV Vaccination Program, because our abstracted data only included birth cohorts from 1891 to 1981. Those vaccinated as infants in 1984 turned 30 years old in 2015 at the earliest, and individuals aged younger than 30 years old precluded from this study due to the paucity of mortality cases at this age. A further reduction in mortality for chronic liver disease and cirrhosis can be anticipated when the vaccine-protected cohorts reach middle and late adulthood.

The successful vaccination program and the antiviral therapy program in Taiwan suggest that other nonviral risk factors, such as cigarette smoking, alcohol consumption, and obesity, may become the next principal targets to control chronic liver disease, liver cirrhosis, and hepatocellular carcinoma. The prevalence of cigarette smoking in adulthood decreased from 2009 to 2015 for both sexes according to a report from the Taiwanese Adult Smoking Behavior Surveillance System [42]. From 2009 to 2013, the prevalence of alcohol consumption decreased slightly for men but increased for women, according to a report from the National Health Interview Survey [43]. The same report also indicated that the prevalence of high triglyceride levels increased from 2001 to 2009 for both sexes [43]. Excessive alcohol drinking is a major cause of liver-related death, accounting for approximately three-quarters of deaths in the USA and Europe $[6,44]$. A recent study revealed that fatty liver, high triglyceride levels, and diabetes mellitus history were significantly associated with hepatocellular carcinoma in patients without $\mathrm{HBV}$ or $\mathrm{HCV}$ infection in Taiwan [45]. These nonviral risk factors have been demonstrated to be critical determinants for hepatocellular carcinoma in other low-endemic HBV regions, such as the UK and the USA $[46,47]$. Because Taiwan is also becoming a low-endemic region for HBV infection, nonviral risk factors for chronic liver disease, liver cirrhosis, and hepatocellular carcinoma warrant attention.

\section{Conclusion}

This study analyzed mortality rates for chronic liver disease and cirrhosis in Taiwan from 1981 to 2015. The National Viral Hepatitis Therapy Program may have contributed to the decrease in mortality rates for chronic liver disease and cirrhosis in adulthood.

\section{Abbreviations}

HBV: Hepatitis B virus; HCV: Hepatitis C virus.

\section{Supplementary Information}

The online version contains supplementary material available at https://doi. org/10.1186/s12963-021-00269-w.

Additional file 1. Figure S1. The age-adjusted liver cancer mortality rates from 1981 to 2015. Figure S2. The age effects from autoregressive ageperiod-cohort analysis of chronic liver disease and cirrhosis mortality for two sexes before and after implementation of national hepatitis therapy program in Taiwan. Table S1. The average annual percentage change of age-adjusted rates and age-specific rates of liver cancer between 1981 and 2003, and between 2004 and 2015 for men and women in Taiwan.

\section{Acknowledgements}

The authors are very thanks for mortality data sharing from the Ministry of Health and Welfare in Taiwan.

\section{Authors' contributions}

LTL and WCL contributed to study design; SYS contributed to collection and analysis of data; all authors contributed to manuscript writing; SYS and WCL contributed to revision of the manuscript. All authors read and approved the final manuscript.

\section{Funding}

This paper is supported by grants from the Ministry of Science and Technology in Taiwan (MOST 105-2314-B-002-049-MY3, MOST 104-2314-B-002118-MY3, MOST 108-2314-B-002-127-MY3 and MOST 108-3017-F-002-001), and the Innovation and Policy Center for Population Health and Sustainable Environment (Population Health Research Center, PHRC) from Featured Areas Research Center Program within the framework of the Higher Education Sprout Project by the Ministry of Education (MOE) in Taiwan (Grant Number NTU-109L900308). No additional external funding was received for this study The funders had no role in the study design, data collection and analysis, decision to publish, or preparation of the manuscript. 


\section{Availability of data and materials}

The datasets used and/or analyzed during the current study are available from the corresponding author on reasonable request.

\section{Declarations}

\section{Ethics approval and consent to participate}

Not applicable.

\section{Consent for publication}

Not applicable.

\section{Competing interests}

The authors declare that they have no competing interests.

\section{Author details}

${ }^{1}$ Institute of Epidemiology and Preventive Medicine, College of Public Health National Taiwan University, Xuzhou Rd., Rm. 536, No. 17, Taipei 100, Taiwan. ${ }^{2}$ Innovation and Policy Center for Population Health and Sustainable Environment, College of Public Health, National Taiwan University, Taipei, Taiwan. ${ }^{3}$ Department of Family Medicine, National Taiwan University Hospital and College of Medicine, National Taiwan University, Taipei, Taiwan. ${ }^{4}$ Taipei Jen-Chi Hospital, Taipei, Taiwan.

Received: 7 October 2018 Accepted: 22 September 2021 Published online: 02 October 2021

\section{References}

1. Marcellin P, Kutala BK. Liver diseases: a major, neglected global public health problem requiring urgent actions and large-scale screening. Liver Int. 2018;38(Suppl 1):2-6.

2. Tsochatzis EA, Bosch J, Burroughs AK. Liver cirrhosis. Lancet. 2014;383:1749-61.

3. Rowe IA. Lessons from epidemiology: the burden of liver disease. Dig Dis. 2017:35:304-9.

4. Murphy SL, Xu J, Kochanek KD, Curtin SC, Arias E. Deaths: final data for 2015. Natl Vital Stat Rep. 2017;66:1-75.

5. Ministry of Health and Welfare, Taiwan, ROC. Statistics of causes of death 2015. https://www.mohw.gov.tw/dl-17921-21c1394d-2c87-45ae-ba8aa3089eb58ed4. Accessed 5 Aug 2016.

6. Global Burden of Disease Cancer C, Fitzmaurice C, Allen C, Barber RM, Barregard L, Bhutta ZA, Brenner H, Dicker DJ, Chimed-Orchir O, Dandona $\mathrm{R}$, et al. Global, regional, and national cancer incidence, mortality, years of life lost, years lived with disability, and disability-adjusted life-years for 32 cancer groups, 1990 to 2015: a systematic analysis for the global burden of disease study. JAMA Oncol. 2017;3:524-48.

7. Blachier M, Leleu H, Peck-Radosavljevic M, Valla DC, Roudot-Thoraval F. The burden of liver disease in Europe: a review of available epidemiological data. J Hepatol. 2013;58:593-608.

8. Chen DS. Hepatocellular carcinoma in Taiwan. Hepatol Res. 2007;37(Suppl 2):S101-105

9. Ministry of Health and Welfare, Taiwan, ROC. Taiwan Public Health Report 2012. http://www.mohw.gov.tw/EN/Ministry/DM2_P.aspx?f_list_no5475\& fod_list_no5853\&doc_no529943. Accessed 16 Aug 2013.

10. Chang MH, Chen CJ, Lai MS, Hsu HM, Wu TC, Kong MS, Liang DC, Shau WY, Chen DS. Universal hepatitis B vaccination in Taiwan and the incidence of hepatocellular carcinoma in children. Taiwan Childhood Hepatoma Study Group. N Engl J Med. 1997;336:1855-9.

11. Lee CL, Ko YC. Hepatitis B vaccination and hepatocellular carcinoma in Taiwan. Pediatrics. 1997;99:351-3.

12. Ni YH, Chang MH, Jan CF, Hsu HY, Chen HL, Wu JF, Chen DS. Continuing decrease in hepatitis $B$ virus infection 30 years after initiation of infant vaccination program in Taiwan. Clin Gastroenterol Hepatol. 2016:14:1324-30

13. Chien YC, Jan CF, Kuo HS, Chen CJ. Nationwide hepatitis B vaccination program in Taiwan: effectiveness in the 20 years after it was launched. Epidemiol Rev. 2006;28:126-35.
14. Chiang CJ, Yang YW, Chen JD, You SL, Yang HI, Lee MH, Lai MS, Chen CJ. Significant reduction in end-stage liver diseases burden through the national viral hepatitis therapy program in Taiwan. Hepatology. 2015;61:1154-62.

15. Ministry of Health and Welfare, Taiwan, ROC. Workshop of causes of death statistics 2009. https://www.mohw.gov.tw/dl-4488-bcd3d71eof78-484e-af83-4cfd0a834126. Accessed 17 Jun 2013.

16. Clayton D, Schifflers E. Models for temporal variation in cancer rates. I: age-period and age-cohort models. Stat Med. 1987;6:449-67.

17. Clayton D, Schifflers E. Models for temporal variation in cancer rates. II: age-period-cohort models. Stat Med. 1987;6:469-81.

18. Lee WC, Lin RS. Autoregressive age-period-cohort models. Stat Med. 1996:15:273-81.

19. Lee LT, Huang HY, Huang KC, Chen CY, Lee WC. Age-period-cohort analysis of hepatocellular carcinoma mortality in Taiwan, 1976-2005. Ann Epidemiol. 2009;19:323-8.

20. Hung TH, Liang CM, Hsu CN, Tai WC, Tsai KL, Ku MK, Wang JW, Tseng $\mathrm{KL}$, Yuan LT, Nguang SH, et al. Association between complicated liver cirrhosis and the risk of hepatocellular carcinoma in Taiwan. PLoS ONE. 2017:12:e0181858.

21. Halliday ML, Coates RA, Rankin JG. Changing trends of cirrhosis mortality in Ontario, Canada, 1911-1986. Int J Epidemiol. 1991;20:199-208.

22. Corrao G. Liver cirrhosis mortality trends in Eastern Europe, 1970-1989. Analyses of age, period and cohort effects and of latency with alcohol consumption. Addict Biol. 1998;3:413-22.

23. Brenner MH. Trends in alcohol consumption and associated illnesses. Some effects of economic changes. Am J Public Health. 1975;65:1279-92.

24. Popkin BM. The nutrition transition and obesity in the developing world. J Nutr. 2001;131:871S-873S.

25. Pingali P. Westernization of Asian diets and the transformation of food systems: implications for research and policy. Food Policy. 2007:32:281-98

26. Caetano R, Laranjeira R. A 'perfect storm' in developing countries: economic growth and the alcohol industry. Addiction. 2006;101:149-52.

27. Sung JL. Hepatitis B virus infection and its sequelae in Taiwan. Gastroenterol Jpn. 1984;19:363-6.

28. Gust ID. Immunisation against hepatitis B in Taiwan. Gut. 1996;38(Supp 2):S67-68.

29. Chen DS, Wang JT, Chen PJ, Wang TH, Sung JL. Hepatitis C virus infection in Taiwan. Gastroenterol Jpn. 1991;26(Suppl 3):164-6.

30. Lee SD, Chan CY, Wang YJ, Wu JC, Lai KH, Tsai YT, Lo KJ. Seroepidemiology of hepatitis C virus infection in Taiwan. Hepatology. 1991;13:830-3.

31. Sheu JC, Wang JT, Wang TH, Wang CY, Yang PM, Huang GT, Shih LN, Lee HS, Chen DS. Prevalence of hepatitis C viral infection in a community in Taiwan. Detection by synthetic peptide-based assay and polymerase chain reaction. J Hepatol. 1993;17:192-8.

32. Yu W, Zhao C, Shen C, Wang Y, Lu H, Fan J. The efficacy and safety of Nucleos(t)ide analogues in patients with spontaneous acute exacerbation of chronic hepatitis B: a systematic review and meta-analysis. PLoS ONE. 2013:8:e65952.

33. Chang TT, Lai CL, Kew Yoon S, Lee SS, Coelho HS, Carrilho FJ, Poordad F, Halota W, Horsmans Y, Tsai N, et al. Entecavir treatment for up to 5 years in patients with hepatitis B e antigen-positive chronic hepatitis B. Hepatology. 2010:51:422-30.

34. Marcellin P, Gane E, Buti M, Afdhal N, Sievert W, Jacobson IM, Washington MK, Germanidis G, Flaherty JF, Aguilar Schall R, et al. Regression of cirrhosis during treatment with tenofovir disoproxil fumarate for chronic hepatitis B: a 5-year open-label follow-up study. Lancet. 2013;381:468-75.

35. Su SY. The impact of national viral hepatitis therapy program and hepatitis B vaccination program on mortality from acute and chronic viral hepatitis in Taiwan. Hepatol Int. 2019;13:157-64.

36. Nishida T, Kobashi H, Fujioka S, Fujio K, Takaguchi K, Ikeda H, Kawaguchi $M$, Ando $M$, Araki Y, Higashi T, et al. A prospective and comparative cohort study on efficacy and drug resistance during long-term lamivudine treatment for various stages of chronic hepatitis B and cirrhosis. J Gastroenterol Hepatol. 2008;23:794-803.

37. Gai XD, Wu WF. Effect of entecavir in the treatment of patients with hepatitis B virus-related compensated and decompensated cirrhosis. Exp Ther Med. 2017:14:3908-14. 
38. Hou JL, Xu D, Shi G, Wan M, Goodman Z, Tan D, Xie Q, Chen C, Wei L, Niu $J$, et al. Long-Term telbivudine treatment results in resolution of liver inflammation and fibrosis in patients with chronic hepatitis B. Adv Ther. 2015;32:727-41.

39. Beasley RP, Hwang LY, Lin CC, Chien CS. Hepatocellular carcinoma and hepatitis B virus. A prospective study of 22707 men in Taiwan. Lancet. 1981:2:1129-33

40. Beasley RP, Hwang LY. Hepatocellular carcinoma and hepatitis B virus. Semin Liver Dis. 1984:4:113-21.

41. Hu YC, Yeh CC, Chen RY, Su CT, Wang WC, Bai CH, Chan CF, Su FH. Seroprevalence of hepatitis B virus in Taiwan 30 years after the commencement of the national vaccination program. PeerJ. 2018;6:e4297.

42. Ministry of Health and Welfare, Taiwan, ROC. Taiwan Tobacco Control Annual Report 2015. https://health99.hpa.gov.tw/flipbook/21806. Accessed 8 Sept 2016

43. National Health Research Institutes, Taiwan, ROC. Report of National Health Interview Survey 2013. http://nhis.nhri.org.tw/files/2013NHIS_ report.pdf. Accessed 22 Mar 2017.

44. Stein E, Cruz-Lemini M, Altamirano J, Ndugga N, Couper D, Abraldes JG, Bataller R. Heavy daily alcohol intake at the population level predicts the weight of alcohol in cirrhosis burden worldwide. J Hepatol. 2016;65:998-1005.

45. Shiu-Feng H, II-Chi C, Chih-Chen H, Tseng-Chang Y, Chao-Long C, Cheng-Chung W, Cheng-Chung T, Ming-Chih H, Wei-Chen L, HsienChung Y, et al. Metabolic risk factors are associated with non-hepatitis B non-hepatitis $C$ hepatocellular carcinoma in Taiwan, an endemic area of chronic hepatitis B. Hepatology Communications. 2018;2:747-59.

46. Hahne S, Ramsay M, Balogun K, Edmunds WJ, Mortimer P. Incidence and routes of transmission of hepatitis B virus in England and Wales, 19952000: implications for immunisation policy. J Clin Virol. 2004;29:211-20.

47. Wasley A, Kruszon-Moran D, Kuhnert W, Simard EP, Finelli L, McQuillan G, Bell B. The prevalence of hepatitis B virus infection in the United States in the era of vaccination. J Infect Dis. 2010;202:192-201.

\section{Publisher's Note}

Springer Nature remains neutral with regard to jurisdictional claims in published maps and institutional affiliations.
Ready to submit your research? Choose BMC and benefit from:

- fast, convenient online submission

- thorough peer review by experienced researchers in your field

- rapid publication on acceptance

- support for research data, including large and complex data types

- gold Open Access which fosters wider collaboration and increased citations

- maximum visibility for your research: over $100 \mathrm{M}$ website views per year

At BMC, research is always in progress.

Learn more biomedcentral.com/submissions 